\title{
Letter: An Economic Evaluation of Iron Isomaltoside 1000 Versus Ferric Carboxymaltose in Patients with Inflammatory Bowel Disease and Iron Deficiency Anemia in Denmark
}

\author{
Ayşegül Aksan (D) · Axel Dignass (D) · Jürgen Stein (D)
}

Received: March 13, 2019 / Published online: June 1, 2019

(c) The Author(s) 2019

Dear Editor,

We read with interest the recent article "An Economic Evaluation of Iron Isomaltoside 1000 Versus Ferric Carboxymaltose in Patients with Inflammatory Bowel Disease and Iron Deficiency Anemia in Denmark" by Pollock and Muduma [1].

The authors present a budget impact analysis (BIA) comparing two intravenous (IV) iron treatments, iron isomaltoside (IIM) and ferric carboxymaltose (FCM) in the treatment of iron deficiency anemia (IDA) associated with inflammatory bowel disease (IBD). The

Enhanced Digital Features To view enhanced digital features for this article go to https://doi.org/10.6084/ m9.figshare.7970675.

A. Aksan $(\bowtie) \cdot J$. Stein

Interdisciplinary Crohn Colitis Clinical Center Rhein-Main, 60594 Frankfurt am Main, Germany e-mail: aksan.a@gmx.de

A. Aksan · J. Stein

Department of Pharmaceutical Chemistry,

University of Frankfurt, 60590 Frankfurt am Main,

Germany

J. Stein

Gastroenterology and Clinical Nutrition, DGD Clinics Sachsenhausen, Schulstrasse 31, 60594

Frankfurt am Main, Germany

A. Dignass

Department of Medicine I, Agaplesion Markus

Hospital, 60431 Frankfurt am Main, Germany objective of the BIA was to evaluate the effects of differences in the respective Summary of Product Characteristics of IIM and FCM on treatment costs in patients with IBD-related IDA from the perspective of the Danish healthcare payer. The BIA is driven by the number of infusions of IIM or FCM needed to administer the calculated total iron requirement in a certain population of patients with IBD-associated IDA. A lower number of infusions implicitly translates into cost savings associated with the iron product used.

In our view, the analysis is based on a number of imaginative but tenuous theoretical assumptions which create a model far removed from the realities observed in clinical trials or routine clinical practice. We believe that both the methodology and the assumptions on which the authors base their analysis have several important weaknesses, which cast considerable doubt on the validity of the results and, ultimately, the conclusions drawn.

There are a number of incorrect or unsubstantiated assumptions driving the model:

1. The Assumption that IIM and FCM are Equal in Efficacy and Safety

The overarching assumption of the analysis is that IIM and FCM have the same efficacy and safety in addressing the iron deficit. To justify their assumption, the authors cite Aksan et al.'s 2017 network metaanalysis comparing the efficacy and safety of 
different IV iron formulations based on randomized clinical trials in patients with IBD-related IDA [2]. Pollock et al. [1]. have, however, seriously misinterpreted the results of the metaanalysis, whose conclusion was unequivocal: "Ferric carboxymaltose was the most effective intravenous iron formulation, followed by iron sucrose. In addition, ferric carboxymaltose tended to be better tolerated. Thus, nanocolloidal IV iron products exhibit differing therapeutic and safety characteristics and are not interchangeable." In the same meta-analysis, it was established that "Rank probabilities in the meta-analysis showed ferric carboxymaltose to be most effective, followed by iron sucrose, iron isomaltoside and oral iron."

In addition, Dr. Aksan and colleagues conclude that, although all IV iron products under consideration in the metaanalysis were more effective than oral iron, statistical significance could be shown only for FCM.

Therefore, the NMA contradicts Pollock and Muduma's assumption of parity in the safety and efficacy characteristics of IIM versus FCM. Since efficacy and safety are key drivers in economic evaluation, a BIA founded upon an unsubstantiated assumption of equivalence must be seriously questioned in terms of the validity of its results and conclusions.

2. Calculation of the Population and Cohort Baseline Characteristics

The authors' calculations regarding population and cohort baseline characteristics for hemoglobin $(\mathrm{Hb})$ and weight of patients with IBD are derived from those reported in the NIMO (Nordic Interaction and Mobility Research Platform) observational study [3]. The study included a total of 233 patients. Pollock et al. base their calculations on the group of IBD patients with anemia, as defined by the World Health Organization $[\mathrm{Hb}<13 \mathrm{~g} / \mathrm{dL}$ (men) and $\mathrm{Hb}<12 \mathrm{~g} / \mathrm{dL}$ (women)] [4]. This group totalled only 100 patients, which, in the absence of a statistical explanation from the authors, appears too small to allow meaningful extrapolation to the BIA population of 3522 patients with IBD and IDA in Denmark.

Parenthetically, it should be noted that the population of the NIMO study was in fact not Danish, but Scandinavian, mainly from Sweden and Norway. Whether the characteristics of Swedish and Norwegian patients are directly comparable to those of the Danish population is unclear and was not addressed by the authors.

3. Dosage Assumption

The authors assume a dosage regimen calculated using a simplified dosing table based on $\mathrm{Hb}$ level and body weight (Table 1). Although this table is recommended for calculation of FCM requirements (although not in every case for IIMsee below), it does not reflect real-life iron dosing. For example, this can be observed in the NIMO study, which reports a total average IV iron dosage of $1010 \mathrm{mg}$. In fact, only $19 \%$ of patients received more than $1000 \mathrm{mg}$ iron during one course of treatment. In contrast, the BIA analysis presumes a total average IV iron dosage of ca. $1400 \mathrm{mg}$, some $40 \%$ higher than the actual observed IIM dose administered to IBD patients with IDA. Furthermore, the safety and efficacy of IIM as a single infusion at this dosage must be considered entirely hypothetical, since $1400 \mathrm{mg}$ infusions have never been investigated in clinical trials of IIM.

The authors' use of the simplified dosing table to calculate total iron requirements is additionally flawed, since the Summary of Product Characteristics for IIM recommends using the Ganzoni formula in

Table 1 IV iron dosing table applied by Pollock et al. in the BIA [1]

\begin{tabular}{|c|c|c|}
\hline \multirow{2}{*}{$\begin{array}{l}\mathrm{Hb} \\
(\mathrm{g} / \mathrm{dl})\end{array}$} & \multicolumn{2}{|l|}{ IV iron dosage (mg) } \\
\hline & $\begin{array}{l}\text { Patients with body } \\
\text { weight } 50 \text { to }<70 \mathrm{~kg}\end{array}$ & $\begin{array}{l}\text { Patients with body } \\
\text { weight } \geq 70 \mathrm{~kg}\end{array}$ \\
\hline$\geq 10$ & 1000 & 1500 \\
\hline$<10$ & 1500 & 2000 \\
\hline
\end{tabular}


patients with bleeding. In patients with IBD, ongoing blood loss from chronically inflamed intestinal mucosa is one of the most common causes of IDA. The use of the simplified dosing table in the analysis thus represents a further possible source of bias, potentially increasing the presumed total IV iron dosage over the 5-year period used in the model, amplifying the difference in the number of required infusions for FCM versus IIM, and thus favoring implicitly higher "cost-savings" for IIM versus FCM.

4. Retreatment period assumption

The retreatment period was calculated from a pooled retrospective analysis [5] of observational follow-up data from three randomized clinical trials (total population available for analysis, 88 patients), which showed anemia to recur within a median of 10 months and iron deficiency within 19 months. Anemia can have multiple causes, iron deficiency being one of them. Since IV iron treatment for anemia is only recommended when iron deficiency is present, the retreatment frequency assumption in the baseline population should have been set at 19 months. By almost halving the appropriate retreatment period (10 months instead of 19), the authors introduce additional bias into the analysis, since the greater frequency leads to a higher total calculated IV iron dosage over 5 years, a higher number of infusions for FCM versus IIM, and implicitly higher "costsavings" for IIM versus FCM. In our estimation, this error would amount to ca. 33\% of the projected cost savings for IIM versus FCM.

With respect to the one-way sensitivity analysis, the authors suggest that switching from an iron deficit calculation based on a simplified dosing table to a Ganzoni dosing approach would further increase cost savings for IIM compared to FCM. This is clearly wrong, as the Ganzoni formula would result in a lower total iron deficit calculation [6] and hence reduce the calculated cost difference.

In conclusion, we suggest that the BIA is very heavily assumption-based rather than evidence- based. Furthermore, the neutrality and reliability of the analysis and the validity of the authors' conclusions are severely undermined by flawed assumptions pertaining to the safety and efficacy of the two products, the extrapolability of baseline population characteristics, the dosage calculation and retreatment period, and the costing methodology.

\section{ACKNOWLEDGEMENTS}

Funding. No funding or sponsorship was received for this study or publication of this article.

Editorial Assistance. The authors thank Janet Collins for editing and proofreading the article. Ms Collins is a paid employee of CED Studien UG at the Interdisciplinary CrohnColitis Center Rhein-Main, Frankfurt am Main, Germany. No other funding was received in connection with the conception, writing, publication, or any other aspect of this article.

Authorship. All named authors meet the International Committee of Medical Journal Editors (ICMJE) criteria for authorship of the article, take responsibility for the integrity of the work as a whole, and have given their approval for this version to be published.

Disclosures. Aysegül Aksan has received payment for research work from Immundiagnostik AG and congress expenses from Vifor Pharma. Axel U. Dignass has received consultancy fees from Abbott, MSD, Ferring, Janssen, Pfizer, Otsuka, Roche/Genentech, Takeda, Pharmacosmos, and Falk Foundation. Dr. Dignass has also received grants from Institut für Gemeinwohl and Stiftung Leben mit Krebs as well as payment for lectures including service on speakers' bureaus from Falk Foundation, Ferring, MSD, Abbott, Janssen, Pfizer, Otsuka, Vifor, Stiftung Leben mit Krebs, Kompetenznetz CED, Takeda and Pharmacosmos. Additionally, A. Dignass has received payment for manuscript preparation from Falk Foundation and payment for development of education 
presentations from Abbott, Pharmacosmos, Falk Foundation and Ferring. Jürgen Stein has received consultancy fees from Abbvie, Fresenius-Kabi, Immundiagnostik, MSD, Pharmacosmos, Takeda, GI Dynamics and Vifor. Dr. Stein has also received payment for lectures from Abbvie, Falk Foundation, Ferring, Immundiagnostik, MSD, Pharmacosmos, Takeda, Thermofischer, GI Dynamics and Vifor. Additionally, Dr. Stein has received payment for manuscript preparation from Abbvie, Falk Foundation and MSD.

Compliance with Ethics Guidelines. This letter is based on previously conducted studies and does not contain any studies with human participants or animals performed by any of the authors.

Open Access. This article is distributed under the terms of the Creative Commons Attribution-NonCommercial 4.0 International License (http://creativecommons.org/licenses/ by-nc/4.0/), which permits any noncommercial use, distribution, and reproduction in any medium, provided you give appropriate credit to the original author(s) and the source, provide a link to the Creative Commons license, and indicate if changes were made.

\section{REFERENCES}

1. Pollock RF, Muduma G. An economic evaluation of iron isomaltoside 1000 versus ferric carboxymaltose in patients with inflammatory bowel disease and iron deficiency anemia in Denmark. Adv Ther. 2018;35: 2128-37.

2. Aksan A, Isik H, Radeke $\mathrm{HH}$, et al. Systematic review with network meta-analysis: comparative efficacy and tolerability of different intravenous iron formulations for the treatment of iron deficiency anaemia in patients with inflammatory bowel disease. Aliment Pharmacol Ther. 2017;45:1303-18.

3. Frigstad SO, Haaber A, Bajor A, et al. The NIMO scandinavian study: a prospective observational study of iron isomaltoside treatment in patients with iron deficiency. Gastroenterol Res Pract. 2017;2017: 4585164 .

4. World Health Organization (2011) Haemoglobin concentrations for the diagnosis of anaemia and assessment of severity. https://www.who.int/vmnis/ indicators/haemoglobin/en/.

5. Kulnigg S, Teischinger L, Dejaco C, et al. Rapid recurrence of IBD-associated anemia and iron deficiency after intravenous iron sucrose and erythropoietin treatment. Am J Gastroenterol. 2009;104:1460-7.

6. Evstatiev R, Marteau P, Iqbal T, et al. FERGIcor, a randomized controlled trial on ferric carboxymaltose for iron deficiency anemia in inflammatory bowel disease. Gastroenterology. 2011;141:846.e1-2-853.e1-2. 